\section{Recurrent intra-abdominal abscess formation due to a gastric diverticulum}

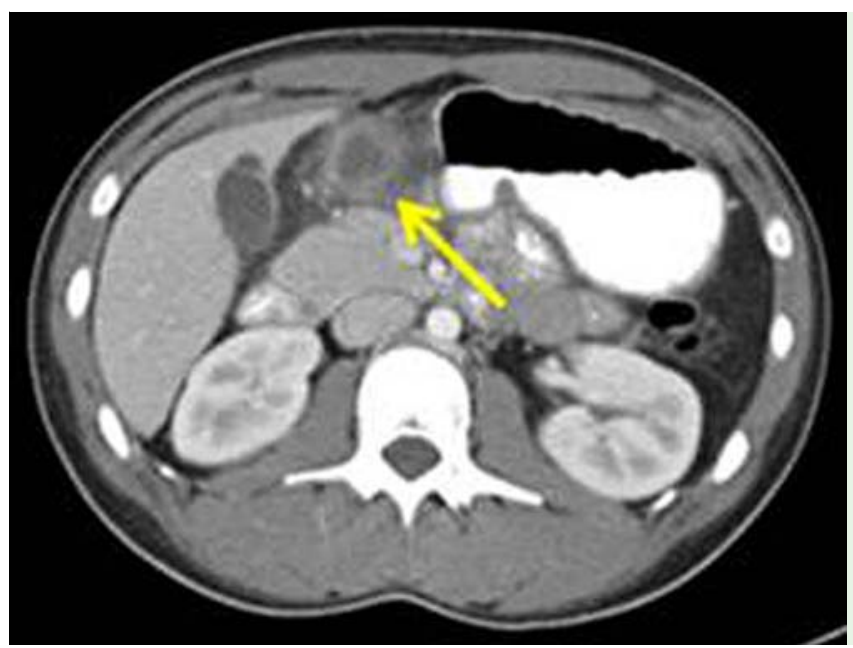

Fig. 1 Computed tomography (CT) scan in a 18 -year-old woman with recurrent abdominal pain showing a thick-walled intra-abdominal fluid collection immediately caudal to the pylorus (arrow), consistent with an abscess.
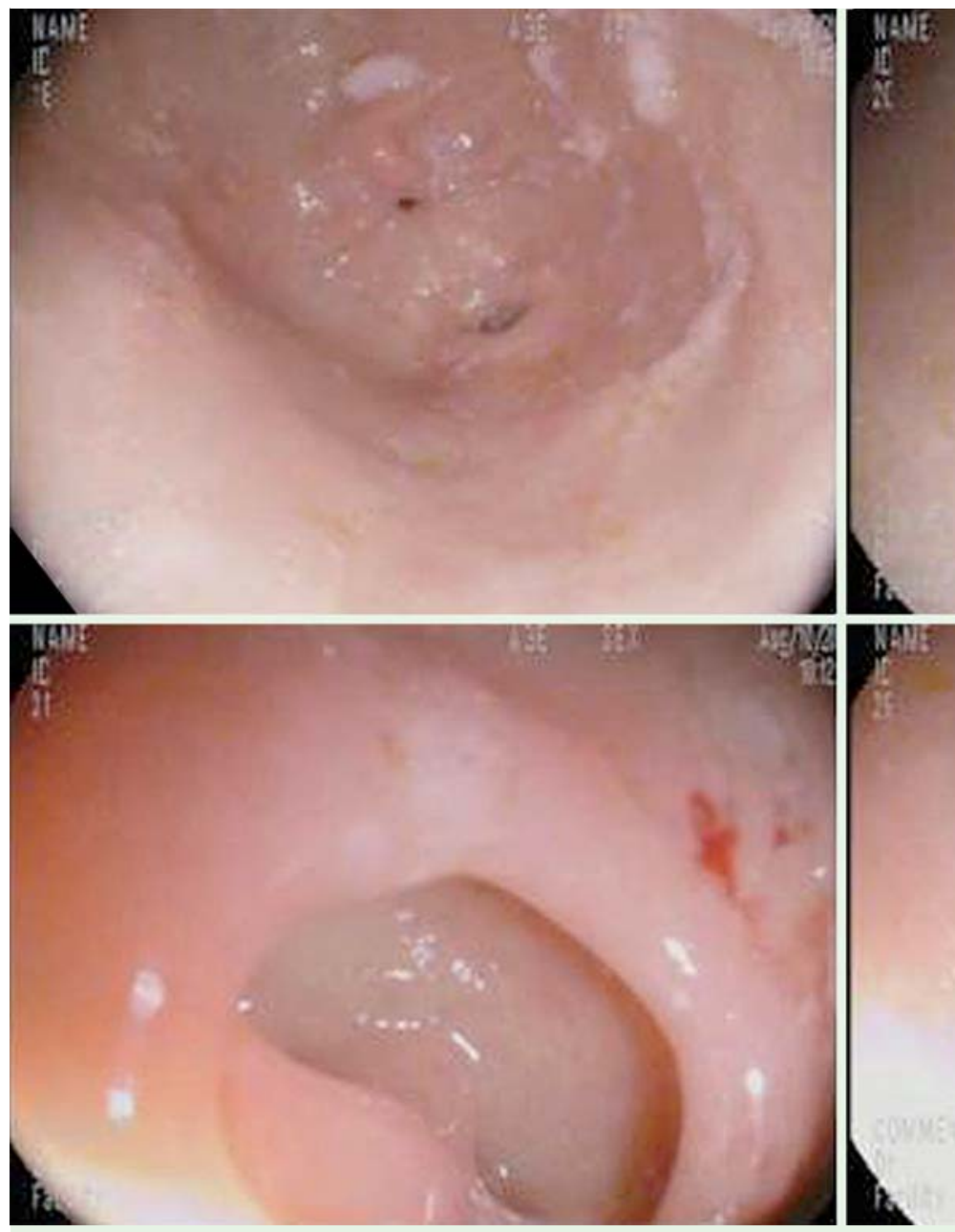

Gastric diverticula are uncommon, usually asymptomatic, and typically present as a solitary diverticulum found incidentally during endoscopy $[1,2]$. Occasionally, gastric diverticula cause symptoms, including pain, bloating, epigastric fullness, bleeding, and perforation. Rarely, they are associated with abscess formation [2-4]. We present a case of a gastric diverticulum complicated by recurrent intraabdominal abscess formation, treated with drainage, antibiotics, and, ultimately, laparoscopic surgery.

An 18-year-old woman with a history of idiopathic intra-abdominal abscess, which was treated with percutaneous drainage and antibiotics, presented with recurrent abdominal pain. She had no other significant medical history. Computed tomography (CT) revealed an abscess near the pylorus of the stomach ( $\bullet$ Fig. 1 ). The abscess was initially drained percutaneously. The patient underwent esophagogastroduodenoscopy (EGD), which showed a diverticulum in the antrum ( $\bullet$ Fig. 2). She

Fig. 2 Endoscopic images of the gastric diverticulum. 
subsequently underwent laparoscopic partial gastrectomy. Pathologic examination revealed a gastric diverticulum with diverticulitis and heterotopic pancreas. There were no postoperative complications.

Gastric diverticula have been found in $0.01 \%-0.11 \%$ of EGD studies [ $1-3]$. True diverticula are typically located at the posterior wall below the gastroesophageal junction, whereas false diverticula are usually found in the distal third of the stomach. True diverticula are thought to be congenital and involve all layers of the stomach wall. Traction or pulsion caused by disease, tumors, or inflammation result in false diverticula, involving only the muscular and serosal layers [1,2]. The diverticulum in our patient was likely acquired, possibly resulting from heterotopic pancreas [5-7]. Heterotopic pancreas is ectopic pancreatic tissue without vascular or anatomic connection to the pancreas, usually found in the stomach, duodenum, and jejunum. It occurs as a result of separation of fragments of tissue from the main body of the pancreas during rotation of the foregut $[6,8]$. Gastric or intestinal wall weakness or traction from the ectopic tissue could lead to development of a diverticulum, as in our patient [7].
Endoscopy_UCTN_Code_CCL_1AB_2AD_3AF

Competing interests: None

\section{Pietrzak', J. Leya ${ }^{1}$, G. Abood ${ }^{2}$, D. Yonick ${ }^{2}$, N. Gupta ${ }^{1}$}

${ }^{1}$ Division of Gastroenterology, Loyola University Medical Center, Maywood, Illinois, United States of America

2 Department of Surgery, Loyola University Medical Center, Maywood, Illinois, United States of America

\section{References}

1 Donkervoort SC, Baak LC, Blaauwgeers LG et al. Laparoscopic resection of a symptomatic gastric diverticulum: a minimally invasive solution. JSLS 2006; 10: 525-527

2 Rashid F, Aber A, Iftikhar SY. A review on gastric diverticulum. World J Emerg Surg 2012; 7: 1

3 McKay R. Laparoscopic resection of a gastric diverticulum: a case report. JSLS 2005; 9: $225-228$

4 Patel SD, Semeraro D, Hall RI. Linitis plastic due to gastric diverticulosis. J R Soc Med 2005; 98: 416-417

5 Christodoulidis G, Zacharoulis D, Barbanis S et al. Heterotopic pancreas in the stomach: a case report and literature review. World J Gastroenterol 2007; 13: 6098-6100
6 Terada $T$. Heterotopic pancreatic tissue of the stomach: report of three cases and consideration of its histiogenesis. Case Rep Gastroenterol 2010; 4: 386-392

7 Tsering L, Zili Z, Rozelle $C$ et al. Gastric antral diverticulum with heterotopic pancreas in a teenage patient. JPGN 2011; 53: 471

8 Sadeghi NR, Godambe A, Shienbaum AJ et al. Premalignant gastric heterotopic pancreas. Gastroenterol Hepatol 2008; 4: 218-221

\section{Bibliography}

Dol http://dx.doi.org/

10.1055/s-0033-1344768

Endoscopy 2013; 45: E345-E346

(c) Georg Thieme Verlag KG

Stuttgart · New York

ISSN 0013-726X

\section{Corresponding author}

\section{Pietrzak}

Loyola University Medical Center

Division of Gastroenterology

2160 S. First Ave, Bldg 54

Maywood

IL 60153

USA

Fax: +1-708-2164113

cpietrz@gmail.com 